\title{
Investigating an isolated serum alkaline phosphatase: an incidental mediastinal seminoma
}

\author{
P Avari1 ${ }^{1}, \mathrm{~K}$ Shapriya ${ }^{1}, \mathrm{R}$ Gordon², A Pokrajac ${ }^{1}$
}

1Department of Endocrinology, Watford General Hospital, West Hertfordshire Hospitals NHS Trust, UK 2Oncology Department, Mount Vernon Hospital, The Hillingdon Hospitals NHS Foundation Trust, UK

\section{INTRODUCTION}

- Serum alkaline phophatase (ALP) may be released from various sources, including liver, bone, thyroid, intestine and placenta.

- We describe a rare case of an isolated serum ALP rise initially dismissed, and later resulting in an incidental finding of a mediastinal seminoma.

- Seminomas account for one-third of testicular germ cell tumors, the most common malignancy in men 15-35 years of age (1); however, primary mediastinal seminoma is rare among extragonadal germ cell tumors (2).

\section{CASE HISTORY}

- A 56-year-old gentleman was referred to the Endocrinology Outpatients by his general practitioner, with a 1-month history of presumed post-viral fatigue and rise in serum ALP.

- He was initially investigated in the outpatient Gastroenterology department with US liver in keeping with two benign liver cysts.

- No interval change seen on imaging and therefore the patient was discharged.

\section{INVESTIGATIONS}

- ALP 296 U/L; ALT 92 U/L; GGT 27U/L; Bili 11 umol/L

- aCa $2.43 \mathrm{mmol} / \mathrm{L}$; phosphate $1.25 \mathrm{mmol} / \mathrm{L}$; Vit-D 55nmol/L

- ESR $45 \mathrm{~mm} / \mathrm{hour}$.

- $\lg$ G $17.2 \mathrm{~g} / \mathrm{dL} ; \operatorname{lgM} 2.45 \mathrm{~g} / \mathrm{dL}$ with slight polyclonal increase in gamma region.

- Autoimmune, thyroid and pituitary profile normal.

- $A L P$ isoenzymes = predominantly bone

- Rising ALP prompted skeletal survey, which showed no bony lesions, but a large anterior mediastinal mass $15.6 \mathrm{~cm}$ $\times 8.6 \mathrm{~cm} \times 14 \mathrm{~cm}$ encasing at least two-thirds of the ascending aorta.

- Staging CT: No other significant lesions found.
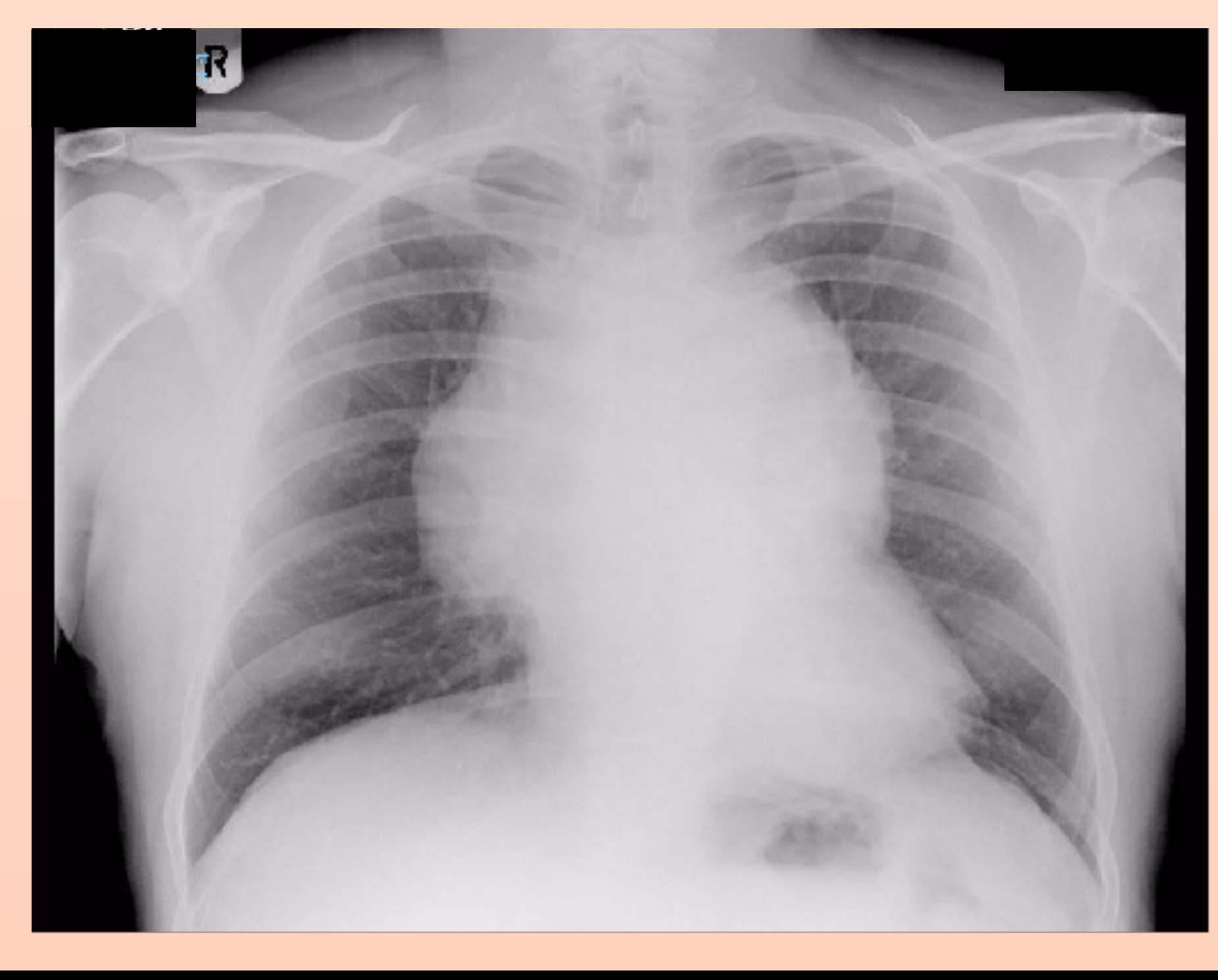
Image 1: Chest $X R$ as part of skeletal
survey showing large anterior mediastinal Iurvey showing large anterior mediastinal

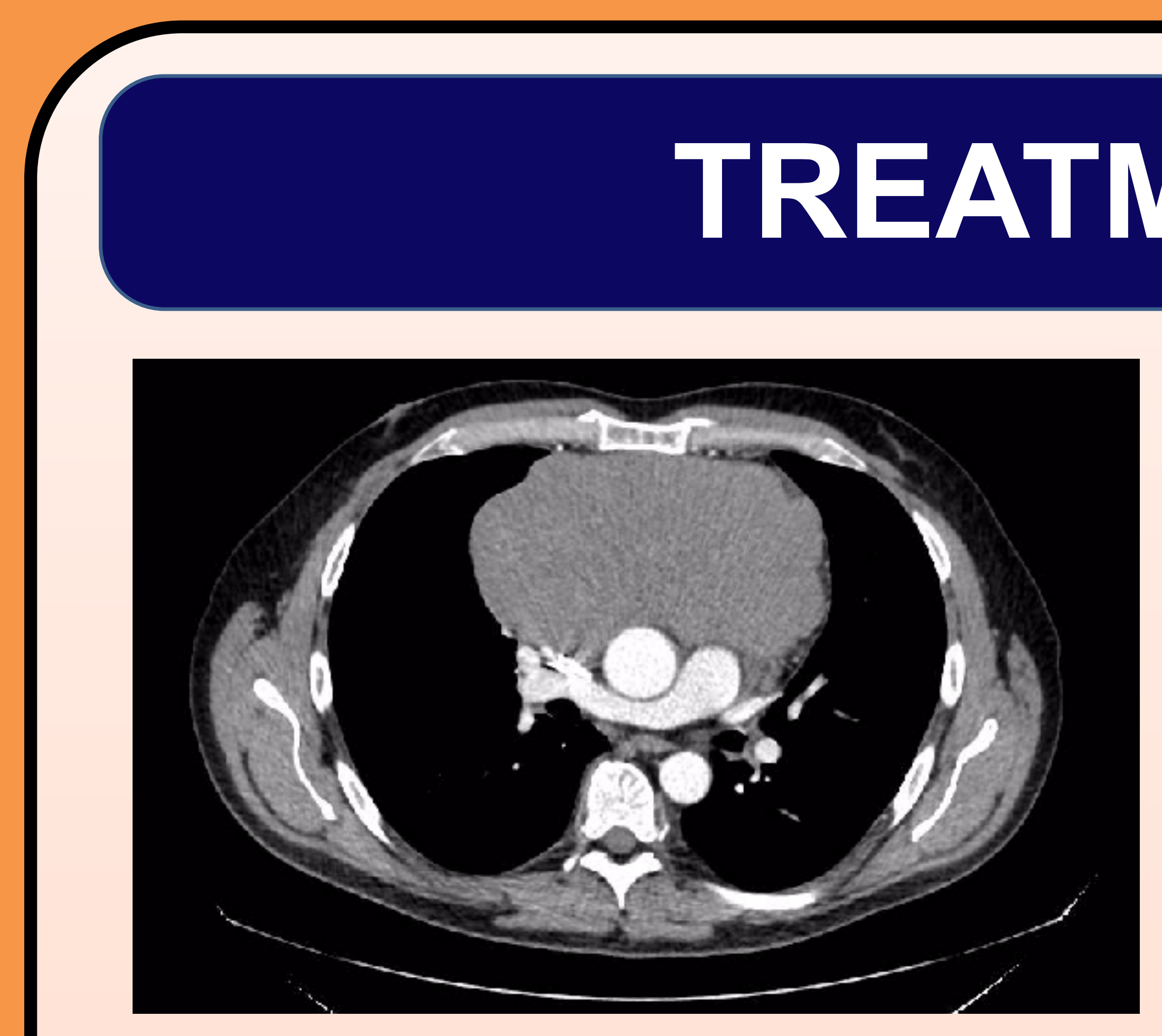

\section{TREATMENT} Image 2: CT imaging axial (left) and coronal (right) views of anterior mediastinal mass revealing large anterior
mediastinal mass $15.6 \mathrm{~cm} \times 8.6 \mathrm{~cm} \times 14 \mathrm{~cm}$ encasing the ascending aorta.

- Diagnostic core biopsy: in keeping with a seminoma, associated with strongly, diffuse positive placental ALP (PLAP), and positive CD5 and CD45.

- He was referred to the Oncologists for further treatment and underwent neoadjuvant chemotherapy (POMB/ACE: cisplatin, vincristine, methotrexate, bleomycin, actinomycin D, cyclophosphamide and toposide) and surgery.

- Two-years on, he remains well with stable residual soft tissue mass retrosternally post surgery.

\section{DISCUSSION}

- Differential diagnosis of a mediastinal mass in the context of an isolated ALP rise, include thymoma, lymphoma and teratoma.

- ALP isoenzymes can help differentiate the source of release (ie. bone, liver, intestine or placenta)

- Seminomas account for approximately one-third of testicular germ cell tumors, with less than $5-7 \%$ of germ cell tumours being extragonadal. They often respond well to radio/chemo-therapy.

- $\mathrm{CT}$ is the recommended imaging modality for the evaluation of most anterior mediastinal masses.

- Prompt diagnosis is paramount to minimise complications. 